\title{
PERCEPÇÃO AMBIENTAL EM ESCOLAS RURAIS: SUBSÍDIOS PARA EDUCAÇÃO AMBIENTAL
}

\author{
Danuza Costa Leite ${ }^{1}$ \\ Thania Maria Fonseca Aires Dourado² \\ Albert Lennon Lima Martins ${ }^{3}$ \\ Joseano Carvalho Dourado ${ }^{4}$ \\ Juliana Silva de Oliveira ${ }^{5}$ \\ Alexandre Giuliano Carrijo ${ }^{6}$
}

Resumo: A percepção ambiental refere-se à forma como o indivíduo concebe o meio ambiente e isso influencia na sua relação com ele. $E$ para realizar ações de Educação Ambiental, antes é necessário que se conheça a percepção ambiental do público alvo. Deste modo, o estudo buscou identificar junto às comunidades escolares do Assentamento São João e do Reassentamento Córrego Prata, a forma como percebem o meio ambiente e os principais problemas ambientais com os quais convivem. Para tanto foi empregada a entrevista semiestruturada e a representação social. Os resultados apontam para uma percepção mais naturalista. Neste sentido, recomenda-se a realização de atividades que possam levar os participantes à conscientização.

Palavras-chave: Percepção Ambiental; Problemas Ambientais; Educação Ambiental.

${ }^{1}$ Fundação Universidade do Tocantins. E-mail: danuza.dcl@gmail.com

2Fundação Universidade do Tocantins. E-mail: thania.mf@unitins.br

${ }^{3}$ Fundação Universidade do Tocantins. E-mail: eng.albertlennon@gmail.com

${ }^{4}$ Fundação Universidade do Tocantins. E-mail: joseano.cd@unitins.br

${ }^{5}$ Fundação Universidade do Tocantins. E-mail: judeoliveira8@hotmail.com

${ }^{6}$ Fundação Universidade do Tocantins. E-mail: alexandre13agro@gmail.com 


\section{Introdução}

Atualmente a sociedade vem se confrontando cada vez mais com questões relacionadas à degradação ambiental, resultante das ações antrópicas, que provocam alterações das características de determinado ecossistema. Sendo que essas alterações podem ser responsáveis por prejuízos (de forma direta ou indireta) à qualidade de vida dos indivíduos (ROSA; SILVA; LEITE, 2009).

Autores como Reigota (1999), afirmam que para compreender e propor qualquer atividade na área ambiental é necessário primeiramente identificar a percepção ambiental, o que permite conhecer a relação do indivíduo com o meio. Oliveira (2006) acrescenta que a realidade de cada um em determinado meio influencia as suas percepções, por isso a importância de compreendê-las.

Para Rosa, Silva e Leite (2009), a Educação Ambiental se constitui em uma ferramenta capaz de induzir modificações na percepção ambiental dos integrantes da sociedade, possibilitando a aproximação com a sustentabilidade. Além disso, permite a construção de uma visão mais ampla de meio ambiente, que leve em consideração o fato de que o ser humano e os ambientes construídos e modificados por ele, também são partes integrantes do meio ambiente.

Estudiosos como Reigota (1999), Guimarães (1998) e Leff (2001), defendem o estabelecimento de uma gestão ambiental em que o conceito de meio ambiente seja visto em sua amplitude natural, cultural, social, econômica e política para que toda a sua complexidade comece a ser entendida.

Para uma eficiente aplicação da Educação Ambiental deve-se levar em consideração a percepção ambiental que os indivíduos possuem sobre o meio em que vivem. Isso está estreitamente relacionado com o ato de conceber e compreender o ambiente, aprendendo a conservá-lo e preservá-lo (FERNANDES et al., 2015).

A Lei Federal no 9795, de 27 de abril de 1999, que define as diretrizes da Política Nacional de Educação Ambiental, aponta a Educação Ambiental como sendo um elemento indispensável da educação nacional, o qual consiste em um conjunto de processos voltados para o propósito da edificação de valores, saberes, ações, capacidades, aptidões, por parte de cada membro da sociedade, que possibilite a preservação do meio ambiente e o desenvolvimento sustentável. Define ainda que a Educação Ambiental "será desenvolvida como uma prática educativa integrada, contínua e permanente em todos os níveis e modalidades do ensino formal' (BRASIL, 1999).

Dessa forma, a pesquisa buscou identificar a percepção ambiental dos integrantes de duas escolas da bacia do Ribeirão São João, cujos resultados poderão ser utilizados como subsídios para a realização de ações que visem conscientizar os atores sociais envolvidos, na busca de soluções para os 
problemas ambientais, tanto por parte da comunidade local organizada, como por partes dos entes públicos da região.

A compreensão de bacia hidrográfica no contexto dessa pesquisa é baseada nos autores Guerra e Guerra (1997, p.75-76), segundo os quais:

bacia hidrográfica é o conjunto de terras drenadas por um rio e seus afluentes [...] A noção de bacia hidrográfica obriga naturalmente a existência de cabeceiras ou nascentes, divisores d'água, cursos d'água principais, afluentes sub-afluentes etc. [...] O conceito de bacia deve incluir também uma noção de dinamismo [...].

E, em Silva (1995), que se refere ao termo bacia hidrográfica como uma compartimentação geográfica natural delimitada por divisores de água. Este compartimento é drenado superficialmente por um curso d'água principal e seus afluentes. Cada bacia hidrográfica se interliga com outra de ordem hierárquica superior, constituindo, em relação à última, uma sub-bacia.

A bacia hidrográfica do Ribeirão São João está localizada na margem direita do reservatório da Usina Hidrelétrica Luís Eduardo Magalhães, nos municípios de Palmas, Porto Nacional e Monte do Carmo, no Estado do Tocantins e compreende uma área de $291,4 \mathrm{~km}^{2}$. Dista $3 \mathrm{~km}$ da área urbana de Palmas, $27 \mathrm{~km}$ de Porto Nacional e $33 \mathrm{~km}$ de Monte do Carmo (DOURADO, 2008).

Estudos realizados na área dessa bacia hidrográfica, por pesquisadores da Fundação Universidade do Tocantins - UNITINS sinalizaram carência de pesquisa em Educação Ambiental, especificamente no Assentamento São João e no Reassentamento Prata, ambos situados nessa bacia hidrográfica, pela necessidade de ações contínuas sobre a temática. Por isso, o público alvo dessa pesquisa consiste nas escolas situadas nessas comunidades: Escola de Tempo Integral Marcos Freire e Escola Municipal Ercina Monteiro Pereira. Neste sentido, as questões orientadoras dessa pesquisa foram: Que percepção as comunidades escolares envolvidas têm de meio ambiente? Quais os principais problemas socioambientais enfrentados?

\section{Metodologia}

O presente estudo foi realizado junto as escolas rurais de duas comunidades localizadas na Bacia do Ribeirão São João: Assentamento São João e Reassentamento Córrego Prata.

O Assentamento São João localiza-se na zona rural de Palmas (TO), a $45 \mathrm{~km}$ do centro da capital, com uma área total de 4.251,97 há. Nesse assentamento está localizada a Escola de Tempo Integral Marcos Freire (figura 1), que apresenta as seguintes coordenadas UTM: 22 L 08080038853645. 
Já o Reassentamento Córrego Prata situa-se no município de Porto Nacional, com uma área equivalente a 3.105 há, distante $44 \mathrm{~km}$ do perímetro urbano e às margens da TO - 050, sentido Porto Nacional/ Palmas. O Reassentamento conta com a Escola Municipal Ercina Monteiro Pereira (figura 2), situada nas coordenas 22 L 07904308844793.

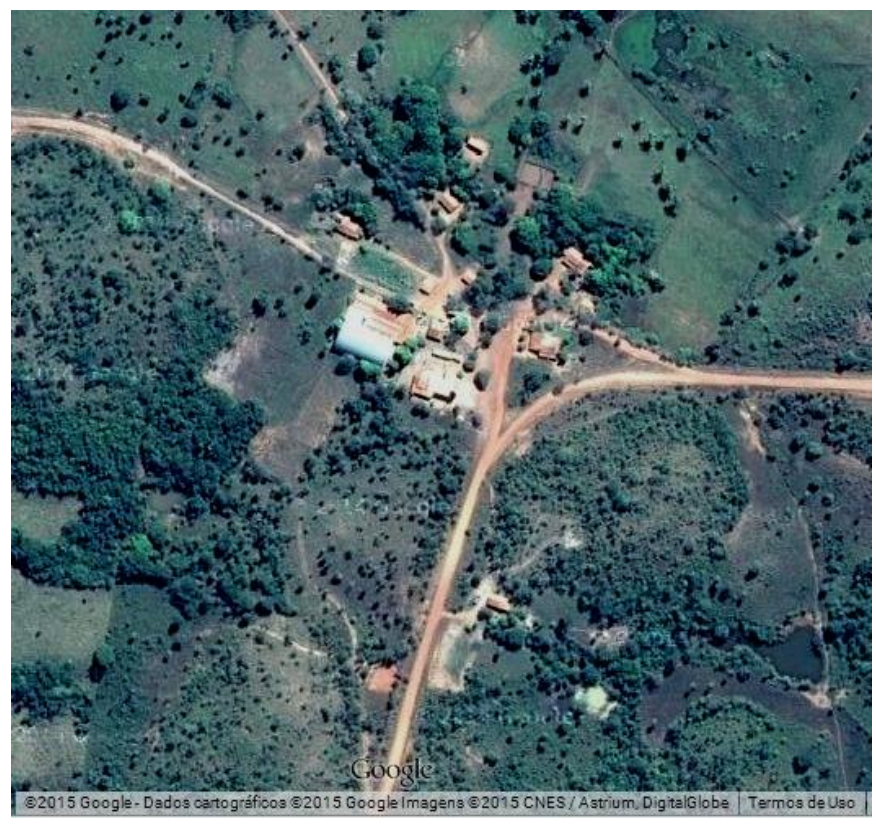

Figura 1: Vista aérea da Escola de Tempo Integral Marcos Freire (no centro) no Assentamento São João. Fonte: GOOGLE MAPS; 2015.

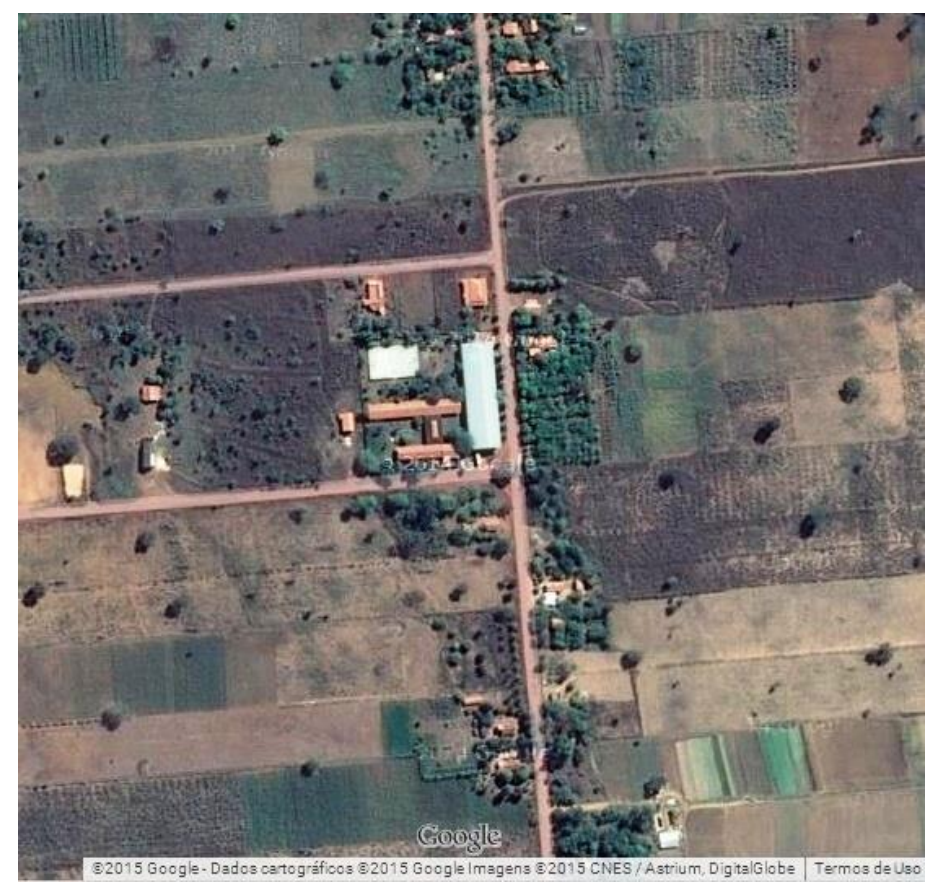

Figura 2: Vista aérea da Escola Municipal Ercina Monteiro Pereira (no centro) no Reassentamento Córrego Prata. Fonte: GOOGLE MAPS; 2015. 
Inicialmente fez-se o levantamento bibliográfico para fundamentação teórica da pesquisa.

Em seguida, foram realizadas visitas preliminares para 0 reconhecimento das áreas de estudo da pesquisa, com o objetivo de expor a proposta do projeto, coletar os contatos das diretoras, e também realizar registros fotográficos, entre outros.

Posteriormente, foi realizado o levantamento de dados no campo por meio do Diagnóstico Rápido Participativo - DRP, que de acordo com Accioly et. al. (2009, p. 12),

é uma técnica que alia a rapidez de um diagnóstico com a participação da comunidade. Este tipo de diagnóstico é utilizado para conhecer e avaliar problemas [...]. Ajuda também a compreender como a população vê sua própria comunidade, seus recursos e suas limitações.

No contexto do DRP foram empregadas as técnicas da entrevista semiestruturada e da representação social. A entrevista semi-estruturada permite descrever e interpretar os fenômenos observados e pode ser aplicada com todos os segmentos da sociedade. Sendo que se fundamenta em questionamentos básicos apoiados em teorias e hipóteses relacionados à temática da pesquisa, cabendo ao entrevistador, agir de forma consciente, redirecionando as respostas para o foco da pesquisa (TRIVIÑOS, 1987). Além disso, nesse tipo de entrevista existe maior flexibilidade, na qual o entrevistador tem a possibilidade de repetir os questionamentos ou esclarecer dúvidas (MARCONI; LAKATOS, 2008).

Já as representações sociais estão associadas ao sentido de reprodução daquilo que se pensa. As representações sociais são portanto, expressões dos pensamentos dos indivíduos por meio de opiniões, atitudes, sentimentos e condutas, produzidas no cotidiano e tem como função promover a interação social. Cintrão e Correia (2004, p.203) ressaltam que o caráter social das representações sociais contribui para os processos de formação de comportamentos.

Para a realização dessa técnica se confeccionou um cartaz (Figura 3) contendo figuras recortadas de revistas, retratando objetos e situações diversas do cotidiano. Foi solicitado ao público-alvo que escolhesse até cinco figuras que melhor representam o meio ambiente. Para Boing ([20--]), por meio dessa técnica é possível identificar como o indivíduo percebe o meio em que vive; fato esse, essencial para a compreensão da relação que ele exerce com a localidade.

Dentro da comunidade da Escola de Tempo Integral Marcos Freire, localizada no Assentamento São João, a representação social foi realizada com os professores, corpo técnico e administrativo, diretora (totalizando 17 pessoas) e com 21 estudantes (amostra aleatória correspondente a 11\%). Nessa escola 
estão matriculados 191 estudantes na primeira e segunda fase do ensino fundamental. Já na Escola Municipal Ercina Monteiro Pereira, situada no Reassentamento Córrego Prata, o método da representação social empregado foi realizado com professores, corpo técnico e administrativo e diretora, num total de 15 pessoas. E com os estudantes, essa técnica de coleta de dados foi executada com 18 discentes $(26,86 \%)$.

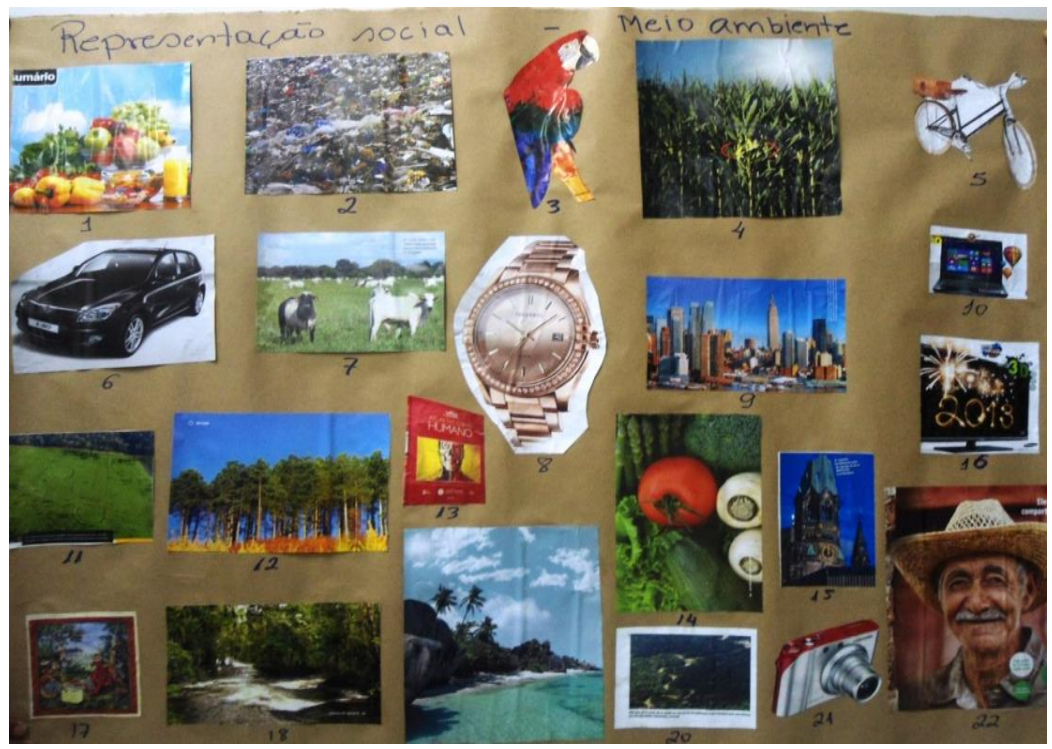

Figura 3: Instrumento de coleta de dados empregado para o levantamento das representações sociais de meio ambiente do público-alvo.

\section{Resultados e reflexão}

Segundo CALIL (2010), pode-se considerar que o meio ambiente é composto pelas seguintes vertentes: meio ambiente natural (sinônimo de natureza, que abrange ar, água, solo, fauna, flora), meio ambiente construído ou artificial (produzido pela ação do homem ao transformar a natureza), meio ambiente cultural (formas de expressão, modos de criar, criações artísticas, científicas e tecnológicas). Baseando-se nisso foi possível categorizar os dados relacionados à percepção ambiental dos integrantes das comunidades, permitindo analisar como se caracteriza a concepção de meio ambiente dos indivíduos.

\section{Escola de Tempo Integral Marcos Freire}

Em relação à percepção ambiental da comunidade escolar composta por professores, corpo administrativo, direção e estudantes, as imagens escolhidas que predominaram correspondem ao meio ambiente natural, equivalente à $88,84 \%$. Enquanto que, a percepção de meio ambiente construído correspondeu a $11,16 \%$ (Figura 4 ). 


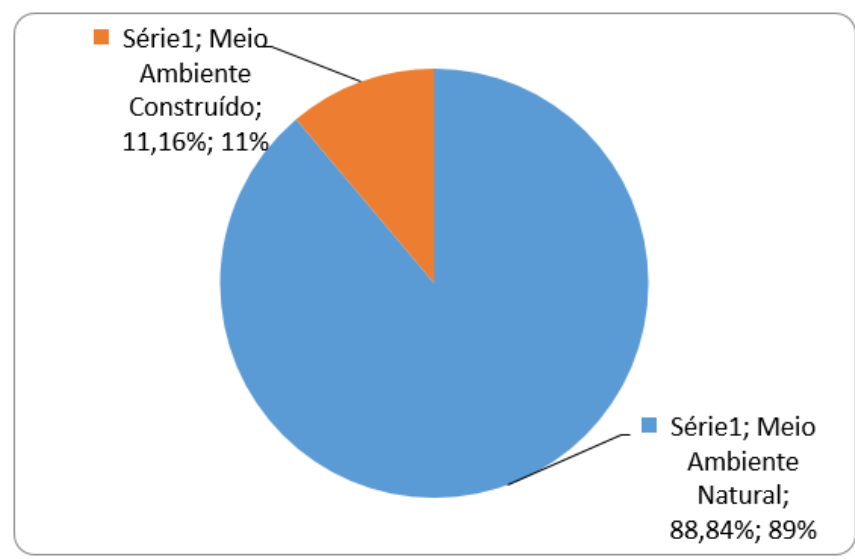

Figura 4: Percepção ambiental dos estudantes, professores, direção e corpo administrativo da Escola de Tempo Integral Marcos Freire.

Também é importante que o indivíduo se perceba como parte do meio ambiente. De acordo com Albuquerque (2007, p. 16), "não devemos enxergar a natureza simplesmente como um conjunto de belas paisagens, animais, plantas e elementos naturais. Ela é a extensão de nosso próprio ser, e nós somos a extensão dela". Essa visão é partilhada por um percentual de 13,15\%.

Quanto aos principais problemas ambientais, foi apontado o aterro sanitário instalado nas proximidades do Assentamento São João, por um percentual de $40 \%$, atribuindo a esse problema a responsabilidade pela possível contaminação das águas dos córregos, o que foi mencionado por $6,67 \%$. A presença de lixo nas margens das estradas de acesso ao Assentamento também foi citado por $6,67 \%$. Porém, o principal problema ambiental apontado pela comunidade foram as queimadas, com $53,33 \%$, isso porque acontecem com frequência, e quando ocorrem causam um impacto mais intenso num intervalo de tempo mais curto (Figura 5).

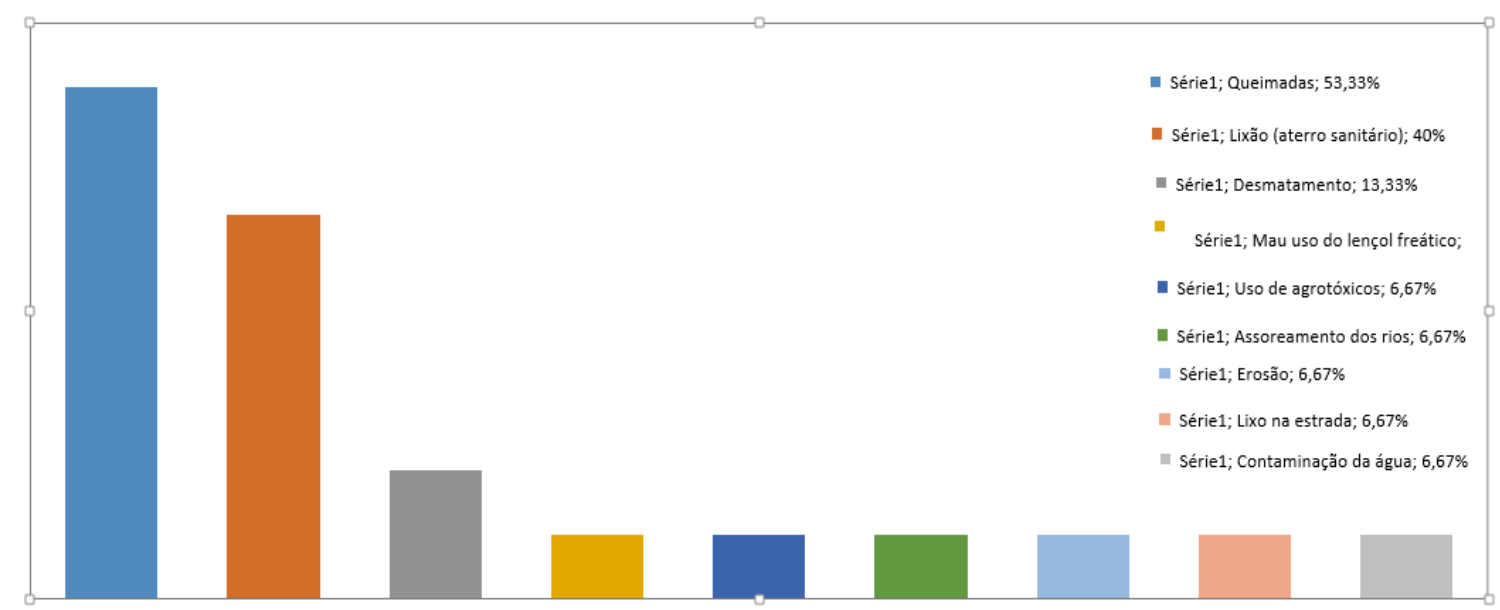

Figura 5: Principais problemas ambientais citados pela comunidade escolar da ETI Marcos Freire. 
Quando indagados sobre as ações que sugerem para amenizar ou resolver os problemas ambientais, predominou a conscientização, registrado junto a um percentual de 53,34\%. Alguns entrevistados ressaltaram que 0 processo de conscientização deveria acontecer por meio de uma Educação Ambiental mais ativa, essa sugestão foi feita por $26,67 \%$ dos entrevistados. Também foi destacada por $13,33 \%$, a transferência do aterro sanitário para outra localidade. Na Figura 6, podem ser observadas outras ações sugeridas pela comunidade escolar da ETI Marcos Freire (Figura 6).

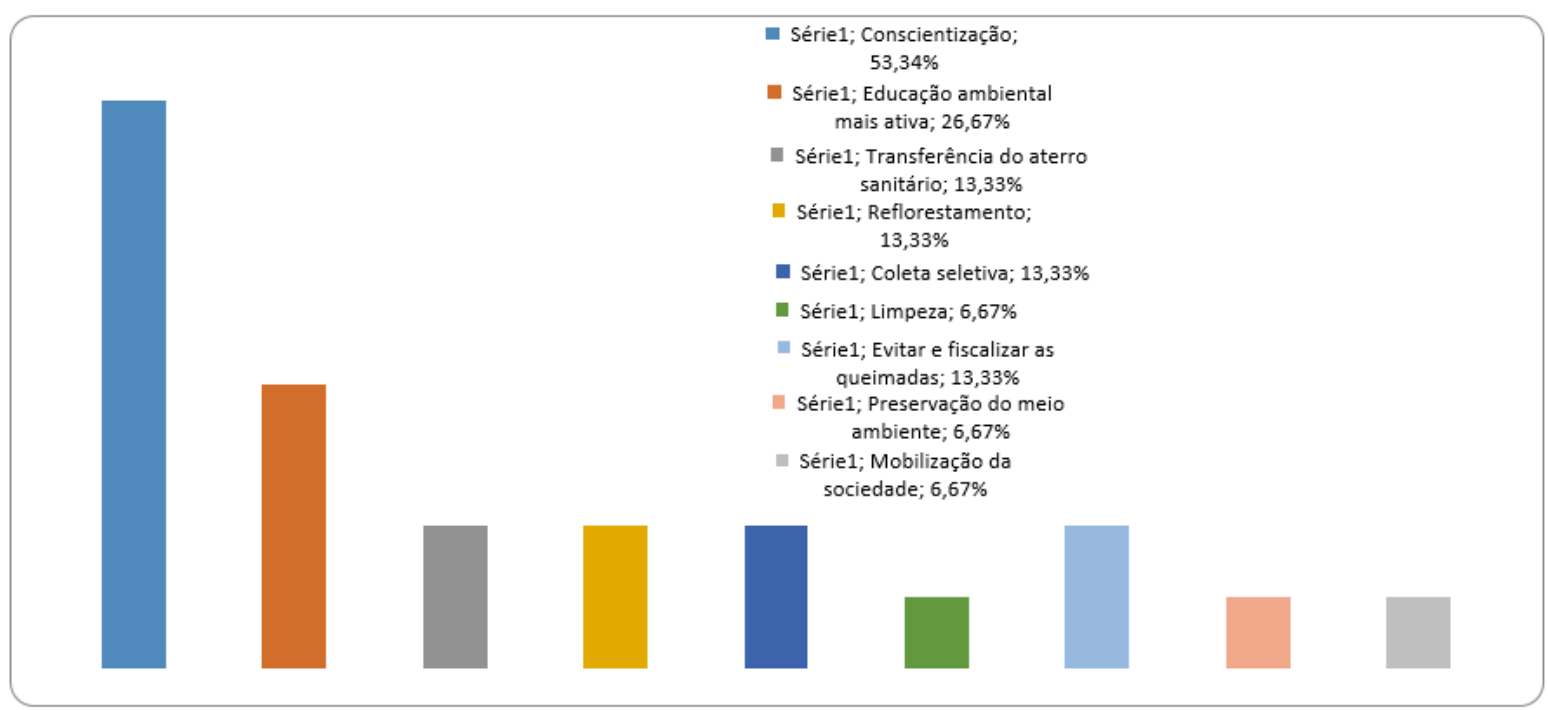

Figura 6: Ações sugeridas pela comunidade escolar da ETI Marcos Freire para a amenização ou resolução dos problemas ambientais.

\section{Escola Municipal Ercina Monteiro Pereira}

Nessa escola foi observada uma visão mais ampla de meio ambiente que engloba o meio ambiente natural, construído e o cultural, com valores correspondentes a $85,62 \%, 10 \%$, e 4,38\%, respectivamente. Esse tipo de percepção se aproxima da definição de meio ambiente da resolução do CONAMA n 306 de 2002, que define o meio ambiente como um "conjunto de condições, leis, influência e interações de ordem física, química, biológica, social, cultural e urbanística, que permite, abriga e rege a vida em todas as suas formas" (BRASIL, p.760, 2002) (Figura 7). 


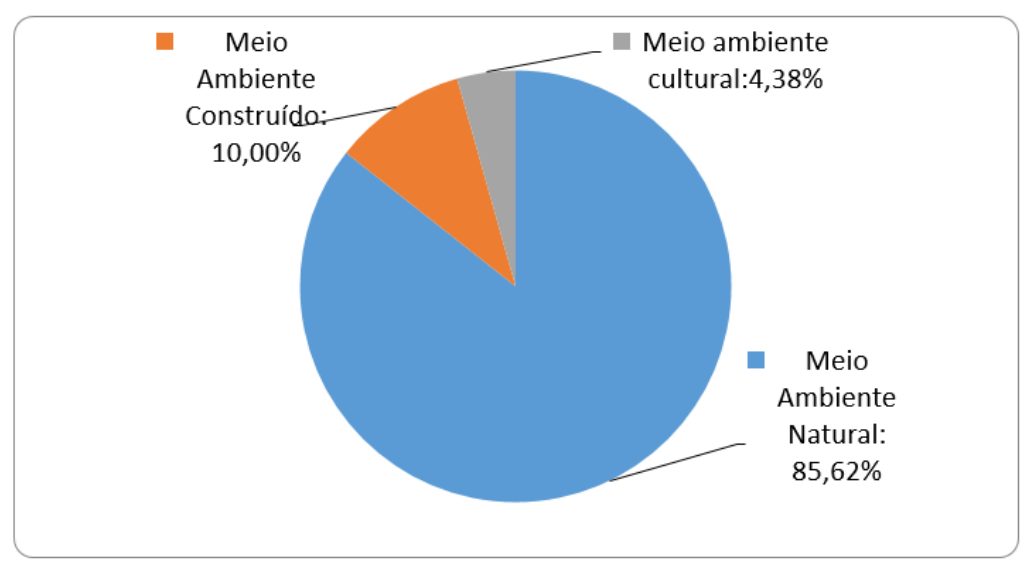

Figura 7: Percepção Ambiental dos estudantes, professores, direção e corpo administrativo da Escola Municipal Ercina Monteiro Pereira.

Vale ressaltar que, nessa escola, o homem foi citado como parte do meio ambiente por um percentual mais significativo, totalizando $18,18 \%$. Porém, grande parte dos entrevistados demonstrou não possuir essa visão. Isso porque o homem pensa e age como se fosse externo ao meio ambiente, o que pode ser a explicação para a exploração irracional dos recursos naturais (SILVA et al., 2002).

Observando os percentuais dos principais problemas ambientais mencionados (Figura 8), verifica-se que o lixo aparece como o mais citado $(50 \%)$, isso pode ser explicado pela ausência de recolhimento de lixo no Reassentamento. Então, uma das soluções que a escola encontra é queimar parte do seu lixo, a outra parte é acondicionada numa vala. Quanto ao lixo orgânico, é levado pelas merendeiras para as suas propriedades, e é utilizado como alimento para animais domésticos.

Também são desafios ambientais: o desmatamento e as queimadas que ocorrem na comunidade (cada uma correspondeu a 42,85\%).

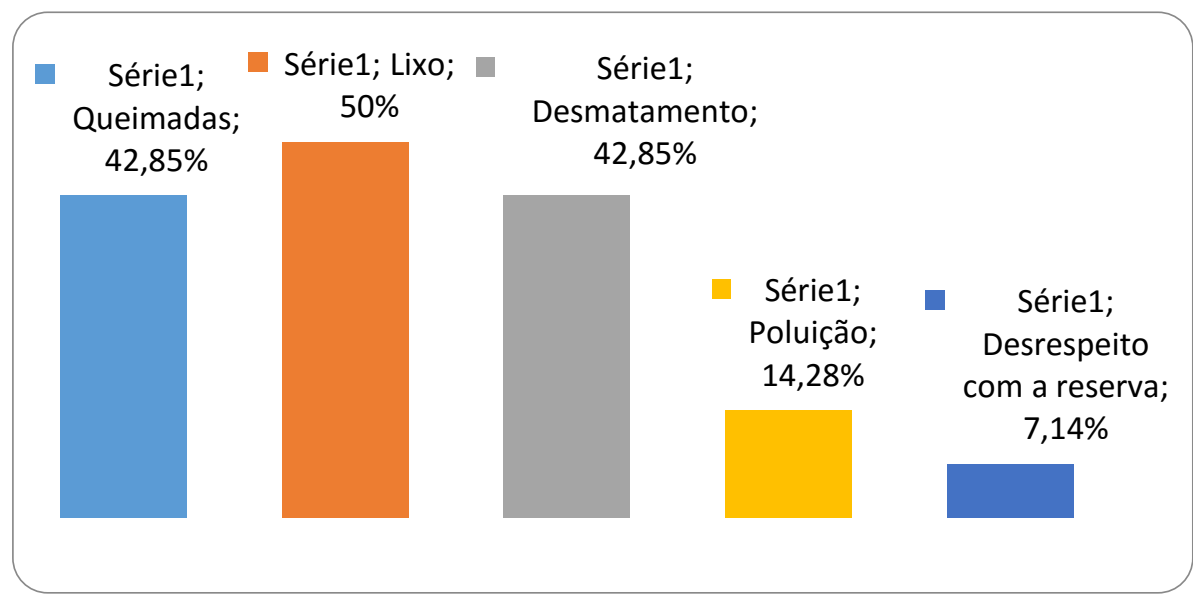

Figura 8: Principais problemas ambientais citados pela comunidade escolar da Escola Municipal Ercina Monteiro Pereira. 
Como solução dos problemas, $21,42 \%$ citou a coleta de lixo, pois como foi citado anteriormente não há recolhimento de lixo nessa localidade.

Destacou-se também o reflorestamento e a redução do desmatamento (visto que esse é um dos principais problemas identificados), cada um com $14,28 \%$.

Vale ressaltar também a destinação correta das embalagens vazias de agrotóxicos, a reciclagem, a redução das queimadas, a iniciativa do poder público, e o aumento da produção de alimentos, que apresentaram percentual de $7,14 \%$ cada uma, como pode ser visualizado na Figura 9.

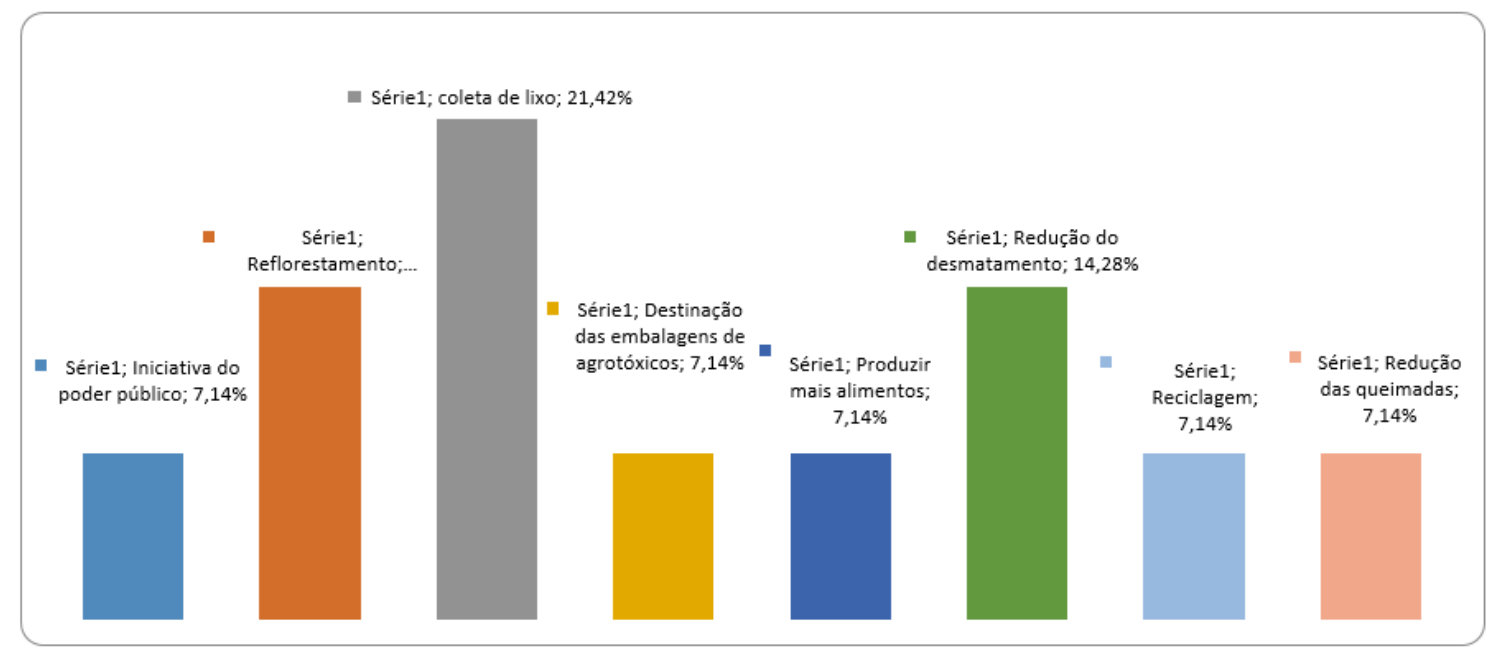

Figura 9: Ações sugeridas pela comunidade da Escola Municipal Ercina Monteiro Pereira para a amenização ou resolução dos problemas ambientais. estudo.

Abaixo estão os registros fotográficos (Figuras 10 e 11) das áreas de

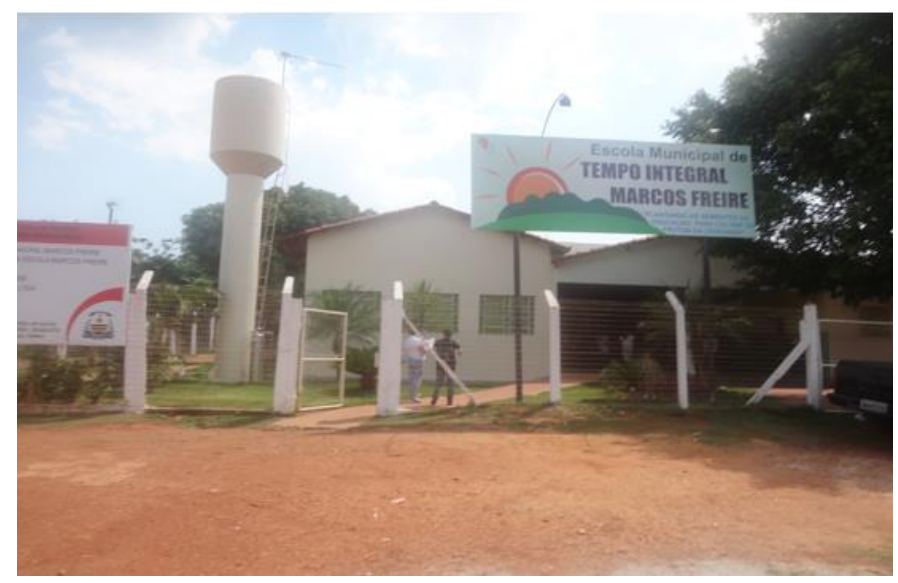

Figura 10: Escola de Tempo Integral Marcos Freire. 


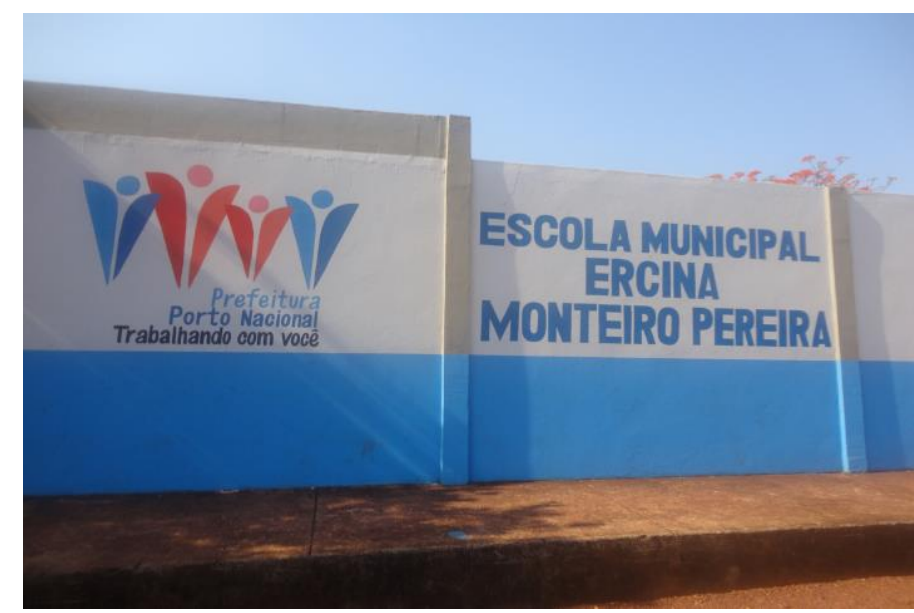

Figura 11: Escola Municipal Ercina Monteiro Pereira.

\section{Conclusões ou recomendações}

A partir das informações coletadas, pode-se dizer que a porção mais significativa do público alvo apresentou uma percepção ambiental mais ligada à natureza. Apesar disso, foi observado que um valor pouco expressivo considera que os ambientes construídos, culturais e o próprio homem fazem parte do meio ambiente, sendo essa uma visão mais sistêmica.

Para modificar essa percepção, recomenda-se a realização de atividades educativas que possam contribuir para a tomada de consciência ambiental pelo público envolvido, por meio de palestras, oficinas, minicursos, nas áreas de queimadas, lixo e desmatamento, principais problemas ambientais identificados em ambas as comunidades.

Igualmente, entende-se que uma conscientização política do problema ambiental envolve não somente as comunidades em referência, mas também a sociedade na qual está inserida, as instituições públicas e privadas, e em especial os órgãos oficiais ligados à questão, pois quando se trata de assuntos de alta complexidade como esse, deve haver uma sintonia entre todos.

\section{AGRADECIMENTOS}

À Deus; à minha família; ao Conselho Nacional de Desenvolvimento Científico e Tecnológico (CNPq), pelo apoio financeiro à pesquisa; à Fundação Universidade do Tocantins. A minha orientadora professora Thania Maria Fonseca Aires Dourado, pela sua orientação, auxílio e paciência. Ao coordenador do projeto Joseano Carvalho Dourado, pela sua ajuda e cooperação. E a todos os amigos pelo empenho e grande colaboração com essa pesquisa: Albert Lennon Lima Martins, Juliana Silva de Oliveira, Alexandre Giuliano Carrijo. E também às Escolas que nos receberam bem e nos apoiaram durante a pesquisa. 


\section{REFERÊNCIAS}

ACCIOLY, A.M.A. et. al. Diagnóstico Rápido Participativo do meio ambiente do Centro Nacional de Pesquisa de Mandioca e Fruticultura Tropical/Embrapa. Cruz das Almas: Embrapa Mandioca e Fruticultura Tropical, 2009.

Disponível em: $<$ http://www.infoteca.cnptia.embrapa.br/bitstream/doc/638693/1/Doc177ld2653 6.pdf>. Acesso em: 14 fev. 2013.

ALBUQUERQUE, B.P. As relações entre o homem e a natureza e a crise sócio-ambiental. Rio de Janeiro: Escola Politécnica de Saúde Joaquim Venâncio, Fundação Oswaldo Cruz (Fiocruz), 2007.

BRASIL. Lei no 9.795 de abril de 1999. Dispõe sobre a Educação Ambiental e institui a Política Nacional de Educação Ambiental. Brasília, DF, 1999. Disponível em: <http://www.planalto.gov.br/ccivil 03/Leis/L9795.htm>. Acesso em: 09 jan. 2013.

BRASIL. Ministério do Meio Ambiente, Conselho Nacional de Meio Ambiente, CONAMA. Resolução CONAMA no 306, de 5 de julho de 2002. Estabelece os requisitos mínimos e o termo de referência para realização de auditorias ambientais. Diário Oficial [da] Republica Federativa do Brasil. Brasília, DF, 19 jul. 2002. Disponível em: <http://www.mma.gov.br> Acesso em: 16 jul. 2013.

CALIL, L.E.S. Vários aspectos do meio ambiente. Disponível em: $<$ http://terrademaosdadas.blogspot.com.br/2010/07/meio-ambiente-

definicoes.html>. Acesso em: 13 mai. 2012.

CINTRÃO, F.F.J.; CORREIA, L. Meio ambiente e representação social: um estudo de caso na escola municipal de ensino fundamental de Araraquara-SP. Revista Uniara, n.14, p. 201-212, 2004.

DOURADO, J.C. Análise ambiental da Bacia do Ribeirão São João: uma contribuição metodológica ao Planejamento e Gestão Ambiental. Tese (Doutorado) - PPGG, Universidade Federal do Rio de Janeiro - UFRJ, 2008.

ESPÍDOLA, M.; RIBEIRO, A.; CRUZ, M. A Percepção Ambiental como subsídio para a formação do sujeito ecológico na comunidade Loteamento Padre Henrique, Várzea Recife PE. Revista de Ciência, Tecnologia e Humanidades do IFPE, v.03, n. 01, jul. 2011.

FERNANDES, R.S.; SOUZA, V.J.; PELISSARI, V.B.; FERNANDES, S.T. Uso da percepção ambiental como instrumento de gestão em aplicações ligadas às áreas educacional, social e ambiental. In: Congresso Brasileiro de Engenharia Sanitária e Ambiental, 23., 2015, Cariacica. Anais... Cariacica: Universidade Federal do Espírito Santo, 2015. p. 1-5. Disponível em: $<$ http://www.bvsde.paho.org/bvsacd/abes23/VI-001.pdf >. Acesso em: 18 mai. 2015. 
GOOGLE MAPS. 2015. Disponível em: shttps://www.google.com/maps/@$10.439441,-48.347222,783 \mathrm{~m} /$ data $=! 3 \mathrm{~m} 1 ! 1 \mathrm{e} 3$ ?hl=pt-BR>. Acesso em: $20 \mathrm{abr}$. 2015.

GOOGLE MAPS. 2015. Disponível em: <https://www.google.com/maps/@$10.3582356,-48.1877843,783 \mathrm{~m} / \mathrm{data}=! 3 \mathrm{~m} 1 ! 1 \mathrm{e} 3 ? \mathrm{hl}=\mathrm{pt}-\mathrm{BR}>$. Acesso em: $20 \mathrm{abr}$. 2015.

GUERRA, A.T.; GUERRA, A.J.T. Novo dicionário geológico geomorfológico. Rio de Janeiro: Bertrand Brasil, 1997.

LEFF, E. Saber ambiental: sustentabilidade, racionalidade, complexidade, poder. 2. ed. Petrópolis: Vozes, 2001.

LAKATOS, E.M.; MARCONI, M.A. Técnicas de pesquisa: planejamento e execução de pesquisas, amostragens e técnicas de pesquisa, elaboração, análise e interpretação de dados. 7. ed. São Paulo: Atlas, 2008.

LIMA, J.G.; ROMANIELLO, M.M.; POZO, O.V.C. Impacto ambiental causado pelo descarte incorreto das Embalagens de agrotóxicos: Um estudo de caso. [S.I.]: UNIFENAS, [20--].

NASCIMENTO, C.R.A. Programa Ética e Cidadania - construindo valores na escola e na comunidade: um estudo de caso. Brasília: Universidade de Brasília, 2008.

OLIVEIRA, N.A. S. A Educação Ambiental e a percepção fenomenológica, através de mapas mentais. Revista Eletrônica do Mestrado em Educação Ambiental. On-line. Curitiba, V. 16, janeiro a junho de 2006. Disponível $<$ http://www.seer.furg.br/remea/article/view/2779/1568>. Acesso em: 18 mai. 2015. ISSN 1517-1256.

ROSA, L.G.; SILVA, M.M.P.; LEITE, V.D. Educação Ambiental em uma escola de formação inicial de nível médio: estratégias e desafios do processo de sensibilização. Revista eletrônica do Mestrado em Educação Ambiental, [S.I.], v. 22, janeiro a julho de 2009.

SILVA, A.M. Princípios Básicos de Hidrologia. Lavras: Universidade Federal de Lavras, 1995.

SILVA, M.M.P. et al. Percepção ambiental de educadores e educadoras do estado da Paraíba/Brasil. Campina Grande: UEPB - Universidade Estadual da Paraíba, 2002.

TRIVIÑOS, A.N.S. Introdução à pesquisa em ciências sociais: a pesquisa qualitativa em educação. São Paulo: Atlas, 1987.

VERDEJO, M.E. Diagnóstico Rural Participativo: Um guia prático. Secretaria da Agricultura Familiar, Brasília, 2006.

WACHELKE, J.F.R.; CAMARGO, B.V. Representações Sociais, Representações Individuais e Comportamento. Revista Interamericana de Psicología/Interamerican Journal of Psychology, Florianópolis, vol. 41, n. 3, p. 379-390, 2007. 